\title{
The human factor as a cause of failures in building structures
}

\author{
Terezie Vondráčková ${ }^{1, *}$, Věra Voštová $^{2}$, and Vladimír Nývlt ${ }^{1}$ \\ ${ }^{1}$ The Institute of Technology and Business in České Budějovice, \\ Okružní 10, 37001 České Budějovice, Czech Republic \\ ${ }^{2}$ Czech Technical University in Prague, Faculty of Transportation Sciences, \\ Horská 3, 12803 Prague 2, Czech Republic
}

\begin{abstract}
Human error can be defined as any unintentional or inadequate decision, taken at any level in the hierarchy of an organization, which is, or was inappropriate in a given situation. Human errors can occur in all human activities across an organization - at a managerial, conceptual or technical level - in connection with mistakes in the construction project itself, mistakes made by the investor, mistakes made by those using the building, mistakes in supplier relations, mistakes in the maintenance of the structure, and others. The factors that can affect the reliability of those people making the decisions that lead to the mistakes include the quality of their education, their experience with stress, or lack thereof, as well as issues such as workload, fatigue, workplace ergonomics, working hours, social climate and private matters.
\end{abstract}

\section{Introduction}

All construction works must be carried out in compliance with the requirements of operational safety, economic efficiency, the environment and in certain cases national security. Safety is one of the basic requirements in modern society. Increasing demand for ever greater efficiency and larger volumes of construction work has seen the gradual introduction of new building technologies and construction techniques. In parallel with this development, increasing standards have been introduced with regards to the quality and safety of operations, in particular in terms of management and logistics. This security depends on the proper management of people and the operation of equipment, as well as the relationship that exists between them.

The reasons for emergencies and accidents on construction sites are well known and documented. These reasons negatively affect the formation and progress of work processes. It is therefore necessary to analyse the prevailing risk factors, or combinations thereof, for the future. At present, several models exist that try to identify and describe the critical factors and interactions between humans and their surroundings [1].

\footnotetext{
* Corresponding author: vondrackova@mail.vstecb.cz
} 


\section{Models for human factors}

The most widely known model is the SHELL model, which was developed in 1972 by Prof. Edward, and subsequently modified in 1975 by Prof. Hawkins. The word SHELL is derived from the initial letters of the model's components (see Figure 1). The components are: $\mathbf{L}$ (Liveware) - the people who use technical equipment, regulations, rules, etc. in their work and who are as individuals at the centre of interest; $\mathbf{H}$ (Hardware) - the equipment and functional systems; S (Software) - the rules, procedures and written documentation; $\mathbf{E}$ (Environment) - the situation in which the L-H-S system must function - the people with whom the individual at the centre of interest is in a relationship with (Liveware) and the working environment (Hardware and Software) in which the interactions take place. The human is an essential and critical element of the management of individual processes.

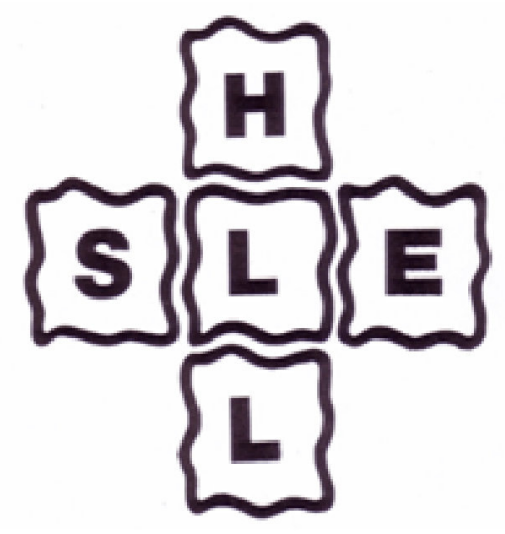

Fig. 1. SHELL model [2].

Another general model that characterizes the role of mistakes at several levels of an organization is the Reason model, alternatively called the Swiss cheese model. Under the model, human mistakes are considered to be a managed risk. If a mistake occurs at a certain level within an organization, and it is not detected and eliminated at another level, this may lead to a critical situation. One of the most sophisticated ways of working with data from road traffic accidents, engineering and manufacturing processes in the Czech Republic is mathematical modelling based on the Bayesian approach. Bayesian statistics is a branch of modern statistics, which works with conditional probabilities and allows for the more precise formulation of hypotheses because other relevant factors are taken into account. It is used very extensively where people work with uncertain knowledge [3].

\section{Risks and causes}

\subsection{Risk sectors in the construction industry}

In a report compiled by the State Labour Inspection it states that the most work-related accidents (43.1\%) and fatalities occur in the manufacturing sector. High-risk industries include construction, transport and storage. Curiously, in 2013, the most common source of fatal work injuries involved ground vehicles and other means of transport, followed by buildings, structures and surfaces. In total, there were 25 fatal work injuries. 


\subsection{Causes of work accidents}

In the majority of cases, work related accidents occur due to poorly or inadequately estimated risks. About $40 \%$ of all fatal accidents are caused by improper organization and safety at work, a lack of awareness among employers, dangerous work practices, actions undertaken without permission or despite an explicit prohibition, or by staying in a hazardous environment. These are reasons for making employers put greater emphasis on staff training, in particular in the area of work safety.

The reliability of any structure is defined as its ability to meet the requirements set out under certain conditions throughout its lifecycle. The safety of any building structure is not only affected by the natural properties of new materials, climate conditions and the like, but also to a large extent by serious mistakes during the development and construction process (see Table 1). Verifying the reliability of a structure on the basis of permitted load or through various methods, be they empirical, probabilistic, or on the basis of partial factors etc., significantly increases the complexity of calculations and therefore the economic burden [4].

Table 1. Causes of failure.

\begin{tabular}{|c|c|c|c|c|c|}
\hline Draft & Implementation & Operation & Other & Human Error & Load \\
\hline $20 \%$ & $50 \%$ & $15 \%$ & $15 \%$ & $80 \%$ & $20 \%$ \\
\hline
\end{tabular}

\section{Work safety and the human factor}

In today's modern and often hectic times, there is huge pressure from all sides not only on workers, but on mankind as a whole. This pressure creates many opportunities, but is also responsible for both psychological and physical problems, the latter being most closely associated with it.

Occupational safety and health has become an important task for every developed society and has become an essential part of working life and the environment. As we continue to create an effective system of prevention both in the technical and occupational hygiene senses, whose purpose is to protect human health and life, it is necessary for every worker to acquire the knowledge and moral sense and responsibility to implement it. In the construction sector, which is very specific in terms of its organization, operations and performance of work, the requirements for the safe performance of work are so extensive that they require special attention. After all, the underestimation of a risk, or the irresponsible behaviour of employees, can result in work accidents that may in some cases be so severe that they can cause permanent injury or even death.

\subsection{Analysis of OSH in specific construction companies [5]}

For the purposes of this analysis two construction companies were approached. They agreed to cooperate on the study on the basis of anonymity. Their names have therefore been changed to BUILDFULL and STAVOBRAVIA respectively. Both companies have branches throughout the Czech Republic and are considered to be large companies with a primary focus on transport and construction. Both companies concentrate on environmental protection and sustainable development.

BUILDFULL was established almost 150 years ago, employs approximately 1,100 workers, and has annual profits of approximately CZK 5 billion. The company operates in the fields of transport and civil engineering. 
STAVOBRAVIA was established almost 80 years ago, employs approximately 1,000 workers, and has annual profits of approximately CZK 4 billion. The company operates in the fields of transport and civil engineering.

Both companies put a high emphasis on quality, environmental protection and reliability. For research purposes the focus was on issues of occupational safety and health $(\mathrm{OSH})$ and on accident rates.

\subsubsection{Work methodology}

The work methodology was divided into two parts. The first part consisted of an anonymous questionnaire. The questionnaire was distributed to the employees of the companies who agreed to participate in the study. They were given sufficient time to complete it. The purpose of the questionnaire and the reason for processing it was given in the introduction. The first few questions referred to general information on the respondent, such as age, gender, etc. The questions that followed were structured in such a way that it was clear that the issue at hand was occupational health and safety being determined between the respondent and their employer. The questions were clearly formulated so that they could be easily understood and the response unequivocal.

The second part was an analysis of documents that the responsible staff in the surveyed companies provided for the research.

The results of the anonymous questionnaire were placed in tables and processed for the analysis of the data. The data was subsequently converted into the form graphs for better presentation and evaluation. By comparing the graphs an assessment was made of how the two companies act in terms of OSH. The same principle was applied to the analysis of the documents, from which emerged a clear evaluation of the factors under scrutiny.

\subsubsection{Anonymous survey}

In total, 30 employees in each of the two companies were sent a questionnaire relating to $\mathrm{OSH}$ at their employer. In total, 28 questionnaires were returned from BUILDFULL, and 30 questionnaires from STAVOBRAVIA. The questionnaires contained 10 questions.

1. Your gender. In BUILDFULL the sample consisted of $64 \%$ men and $36 \%$ women; In STAVOBRAVIA the sample consisted of $50 \%$ men and $50 \%$ women.

2. Your age. The largest age group was between 36-55 years, with the lowest proportion of respondents in the age group 25-35 years. The results were almost identical for both companies.

3. Interested in the issue of OSH. If we want to effectively reduce accident rates, it is important that the issue of occupational health and safety is approached by the staff in a responsible and positive manner. The results are presented in Figure 2. The results show a lack of interest or less interest in OSH within the companies. This may be the result of apathy towards training, a lack of motivation on the part of the employer or the unwillingness of employees.

4. The role of $\mathrm{OSH}$. The results are presented in Figure 3.

5. Health and safety training at your employer? For both surveyed companies, 68\% regularly participate in relevant training.

6. The impact of the training. In BUILDFULL $70 \%$ of the respondents considered trainings beneficial. The employees of STAVOBRAVIA were all satisfied.

7. The frequency of training. The results show that $10 \%$ of the 58 respondents were dissatisfied. This is therefore clearly an issue that both companies need to address. 
8. First aid kit in your workplace. Only one person from both companies knew whether there was a first aid kit in their workplace. This shows gross ignorance of one of the basic principles of safety, which must be tackled.

9. Identifying and preventing OSH risks. In both companies, $15 \%$ of employees ticked the answer "do not know". It is clear that both the employees and employers are at fault on this issue.

10. Critical day of the week. The critical days were Mondays and Fridays.

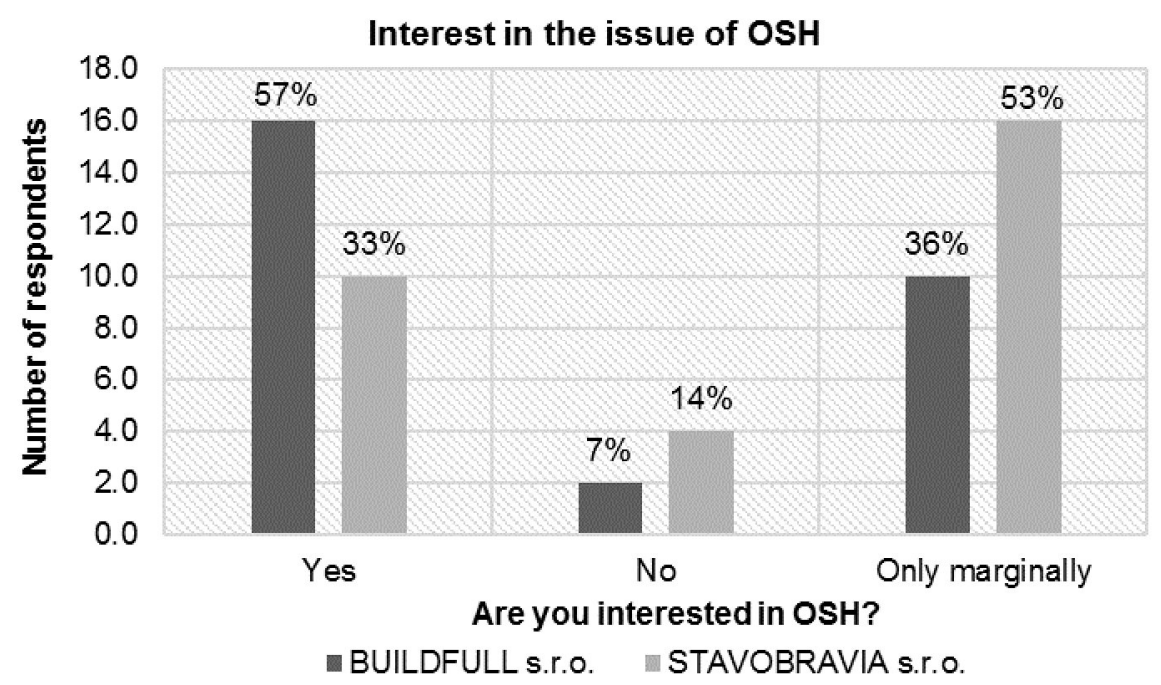

Fig. 2. Results of interest in the issue of OSH.

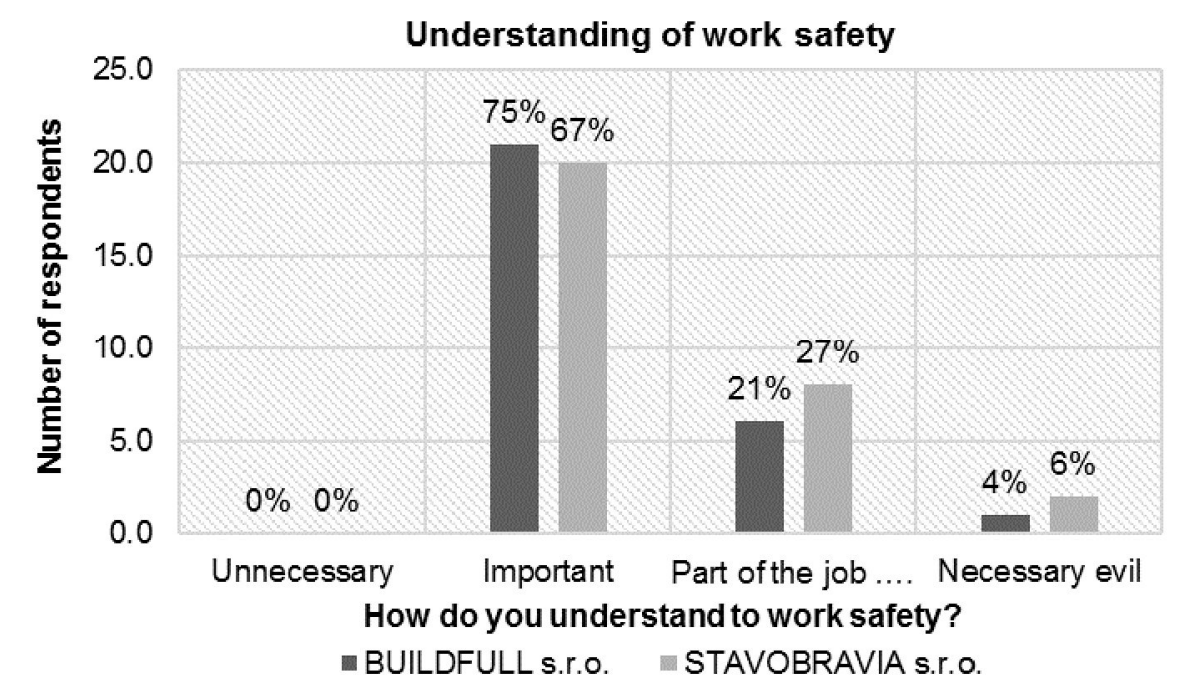

Fig. 3. Results of understanding of work safety. 


\subsection{Statistical analysis}

The results in this section are based on an analysis of the occupational injuries over the past 6 years. Due to the similarity of the two companies in terms of the number of employees and their organizational structure, individual areas can be compared very well.

1. The number of accidents in the period 2010-2015. For both companies, consideration was given to the number of employees in each evaluated year, with the number of accidents and the frequency of accidents being given per 100 employees. The results are presented in Figure 4.

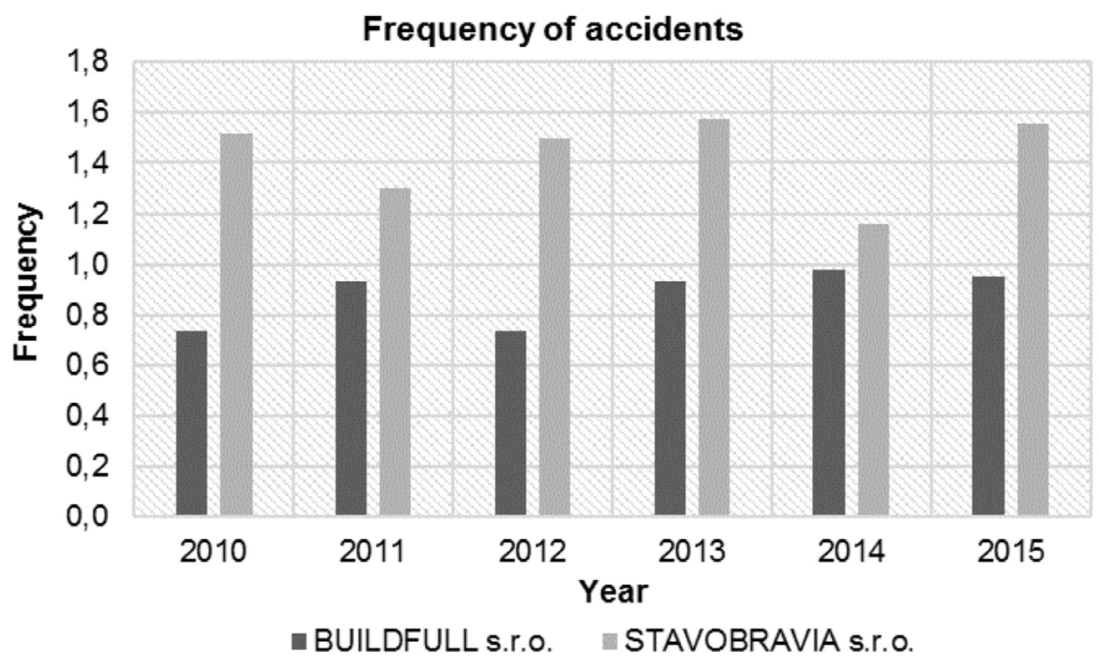

Fig. 4. Frequency of accidents from 2010 to 2015.

2. The costs of purchasing personal protective equipment (PPE). The results of the analysis show that the average annual cost for the purchase of PPE is approximately CZK 2,500 per employee per company.

3. The number of missed working days per year in period 2010-2015. In BUILDFULL the number was consistently around 350 days per year, whereas in STAVOBRAVIA it ranged from 300 to 400 days per year.

4. The number of incurred injuries in the period 2010-2015 according to the days of the week. From the research, it was clear that the most critical days are Mondays and Fridays. Saturdays and Sundays are the days with the minimum risk of accidents due to the fact that there are fewer workers on sites.

5. The division of occupational injuries by age group. In BUILDFULL the most accidents occurred in the age group 51 years and over. This result provides evidence of the fact that although the older should be more experienced and capable of recognizing and estimating risks in their activities, the opposite is true and that the situation is very often underestimated. The situation was similar in STAVOBRAVIA, where most accidents occurred in the age group 41-50 years. In both companies, the least accidents were recorded in the age group 18-30 years. 


\subsection{Discussion}

The willingness on the part of the two companies to participate in the anonymous questionnaire survey shows that both companies are interested in the issue of OSH and deem it important and a part of their responsibilities. The results of the analyses show that both companies need to focus more on the concept and the content of the health and safety training they provide and, for example, use surveys to determine which information, notices or other aspects of the training the staff lack. Depending on these findings, the awareness of the employees should be raised. This should or could be part of regular OSH training sessions, or could possibly be the subject of one-off information sessions regarding the operation and facilities of the individual companies. The companies also need to thoroughly analyse their accident rates i.e. focus on the nature of individual accidents in order to reduce future risks and making it easier to prevent accidents. The research shows that although it might seem that older workers should be more experienced and more able to estimate the potential risks, the opposite is true. As a response to this, companies should concentrate on workers in the age group 41 years and over this group.

\section{Conclusion}

The human factor is a concept that is increasingly encountered both in the professional workplace as well as in the media. It is a "set of characteristics and the abilities of a human being, mainly psychological and physiological, that in some way in a given situation affects the performance, efficiency and reliability of the system of work." It is necessary to take into consideration that the concept of the human factor not only relates to individuals, but to groups, which determine the level of security (both in a company and in society) in terms of the depth of corporate culture, safety culture and societal culture. Managers in companies should therefore focus on this phenomenon because in it lies one of their weakest links.

Occupational safety and health is a very broad field that involves extensive regulations, standards, laws, etc. If it is in any way possible to eliminate risks and protect human health and life, it is necessary to develop this sector and strive for the greatest fulfilment of its objectives.

\section{References}

1. S. Szabo, Journal of Applied Economic Sciences 10, 1153-1159 (2015)

2. Lidský činitel v letecké dopravě, available on http://projekt150.ha-vel.cz/node/117

3. R. Štecha, Human Factors Classification in Air Traffic Control (Disseration thesis, Czech Technical University in Prague, Faculty of Transportation Sciences (2013)

4. T. S. Ferry, Modern Accident Investigation and Analysis (New Jersey, John Wiley and Sons, 1988)

5. L. Homolková, Analýza BOZP ve zvolené stavební firmě v časovém horizontu 5 let (Bachelor thesis, Institute of Technology and Business in České Budějovice, 2016) 